Check for updates

Cite this: Mater. Adv., 2022, 3, 1574

Received 13th September 2021, Accepted 19th December 2021

DOI: 10.1039/d1ma00842k

rsc.li/materials-advances

\title{
High temperature thermo-mechanical properties of praseodymium doped ceria thin films measured two ways $\dagger$
}

\author{
Yuxi Ma, (D) Quan Zhou (D) and Jason D. Nicholas (D)*
}

\begin{abstract}
The temperature dependence of a mixed ionic electronic conducting (MIEC) material's thermo-chemical expansion coefficient, biaxial modulus, and/or Young's modulus are crucial in determining the internal stress, strain, and/or mechanical stability of the various electrochemical devices (batteries, fuel cells, gas sensors, etc.) utilizing them. This work compares the temperature-dependent thermo-chemical expansion coefficient, biaxial modulus, and Young's modulus of $\operatorname{Pr}_{0.1} \mathrm{Ce}_{0.9} \mathrm{O}_{1.95-\delta}$ (10PCO) MIEC thin films obtained using two different techniques: (1) a "dual substrate" technique where in-plane stress measurements were collected on "identical" 10PCO thin films atop two different substrate compositions, and (2) a "dual characterization" technique were out-of-plane strain measurements and in-plane stress measurements were performed on a single sample. Both techniques indicated that from 500 to $700{ }^{\circ} \mathrm{C}$ (1) the average 10PCO thermo-chemical expansion coefficient in the (100) plane increased from $\sim 12.5$ to $\sim 17.5 \mathrm{ppm}$, (2) the 10PCO biaxial modulus in the (100) plane was roughly constant at $\sim 300 \mathrm{GPa}$, and (3) the average 10PCO Young's modulus in the (100) plane was roughly constant at $\sim 175 \mathrm{GPa}$.
\end{abstract}

\section{Introduction}

Ceria and doped ceria have been widely used as oxygen exchange materials in solid oxide fuel cells (SOFCs), ${ }^{1}$ solid oxide electrolysis cells (SOECs), ${ }^{2}$ solar thermo-chemical cells, ${ }^{3}$ catalytic converters, ${ }^{4}$ chemical sensors, ${ }^{5}$ oxide memristors, ${ }^{6}$ oxygen separation membranes, ${ }^{7}$ and other electrochemical devices. ${ }^{8}$ Due to ceria's point defect chemistry ${ }^{9-11}$ and low oxygen surface exchange kinetics near room temperature, ${ }^{10,12,13}$ ceria is most often used several hundred degrees above room temperature. As a result, information on ceria's temperature-dependent thermo-chemical expansion behavior and temperature-dependent elastic properties is critical for determining the internal stress, strain, and mechanical stability of various ceria-based devices. Unfortunately, the difficulty of conducting in situ high-temperature mechanical property measurements has limited the number of reports on ceria's hightemperature mechanical properties.

Hence, this work measured and compared the temperaturedependent thermo-chemical expansion coefficient $(\alpha)$, biaxial modulus $(M)$, and Young's modulus $(E)$ of $\mathrm{Pr}_{0.1} \mathrm{Ce}_{0.9} \mathrm{O}_{1.95-\delta}$ (10PCO) thin films obtained using two different techniques.

Michigan State University, Chemical Engineering and Materials Science Department, 2100 Engineering Building, 428 S. Shaw Lane, East Lansing, MI 48824, USA. E-mail: jdn@msu.edu

$\dagger$ Electronic supplementary information (ESI) available. See DOI: 10.1039/d1ma00842k
In the first "dual substrate" (DS) technique, $\alpha, M$, and $E$ were determined from elevated-temperature in-plane stress measurements collected on "identically-produced" 10PCO thin films atop two different substrates with very different thermal expansion coefficients. In the second "dual characterization" (DC) technique, $\alpha, M$, and $E$ were determined from elevatedtemperature out-of-plane strain measurements and in-plane stress measurements performed on a single sample.

\section{Theory}

\section{Dual substrate technique overview}

As detailed previously, ${ }^{10,14-16}$ the "dual substrate" technique determines a film's thermo-chemical expansion coefficient $\left(\alpha_{\mathrm{f}}\right)$ and a film's biaxial modulus $\left(M_{\mathrm{f}}\right)$ generally defined for any material as:

$$
\begin{gathered}
\alpha=\left(\frac{1}{a_{25}}\right)\left(\frac{\partial a}{\partial T}\right) \\
M=\frac{E}{1-v_{\mathrm{f}}}
\end{gathered}
$$

respectively (where $a$ is an arbitrary length, $T$ is temperature in Celsius, 25 denotes $25{ }^{\circ} \mathrm{C}$, $v$ is the Poisson's ratio, and the other variables have their previously defined meanings), from the measured instantaneous change in the in-plane biaxial film 
stress $\left(\sigma_{\mathrm{f}}\right)$ for a change in temperature $(\Delta T)$ for two "identical" films on substrates with very different thermal expansion coefficients (CTE's). This is achieved by plugging the equation for the amount of CTE-mismatch-induced strain in the film $\left(\varepsilon_{\mathrm{f}}\right)$ induced by substrate 1 or substrate 2 :

$$
\begin{aligned}
& \varepsilon_{\mathrm{f}}=\left(\alpha_{1}-\alpha_{\mathrm{f}}\right) \Delta T \\
& \varepsilon_{\mathrm{f}}=\left(\alpha_{2}-\alpha_{\mathrm{f}}\right) \Delta T
\end{aligned}
$$

into the thin film version of Hooke's Law:

$$
\sigma_{\mathrm{f}}=M_{\mathrm{f}} \varepsilon_{\mathrm{f}}
$$

and differentiating the result to yield two equations, with two unknowns $\left(\alpha_{\mathrm{f}}\right.$ and $\left.M_{\mathrm{f}}\right)$ :

$$
\begin{aligned}
& \frac{\partial \sigma_{1}}{\partial T}=M_{\mathrm{f}}\left(\alpha_{1}-\alpha_{\mathrm{f}}\right) \\
& \frac{\partial \sigma_{2}}{\partial T}=M_{\mathrm{f}}\left(\alpha_{2}-\alpha_{\mathrm{f}}\right)
\end{aligned}
$$

that can be solved simultaneously for $\alpha_{\mathrm{f}}$ and $M_{\mathrm{f}}$, assuming the substrate thermo-chemical expansion coefficients $\left(\alpha_{1}\right.$ and $\left.\alpha_{2}\right)$ are known. $E_{\mathrm{f}}$ can then be extracted from $M_{\mathrm{f}}$ via eqn (2) and knowledge of the film's Poisson's ratio.

\section{Dual characterization technique overview}

As described previously, ${ }^{17}$ the "Dual characterization" technique determines a film's $\alpha_{\mathrm{f}}$ and $M_{\mathrm{f}}$ through comparison of the out-of-plane film strain $\left(\varepsilon_{z}\right)$ and the in-plane film stress $\left(\sigma_{\mathrm{f}}\right)$. Specifically, the out-of-plane strain can be expressed as the sum of (1) the thermo-chemical film strain in the out-of-plane direction, and (2) the $z$-direction Poisson strain caused by inplane strain induced by a change in temperature $(\Delta T)$ and the coefficient of thermal expansion (CTE) mismatch between the film and substrate $\left(\alpha_{\mathrm{s}}-\alpha_{\mathrm{f}}\right)$, via the equation:

$$
\varepsilon_{z}=\alpha_{\mathrm{f}} \Delta T-\frac{2 v}{1-v}\left(\alpha_{\mathrm{s}}-\alpha_{\mathrm{f}}\right) \Delta T
$$

assuming the same directionally-averaged $\alpha_{\mathrm{f}}$ in the plane of the film and in the plane perpendicular to the film (which was assumed to the case for the high-temperature, lightly strained (i.e. still cubic) ${ }^{18}$ (100)-oriented ceria films analyzed here). Differentiating eqn (6) allows $\alpha_{\mathrm{f}}$ to be determined from the measured $\frac{\partial \varepsilon_{z}}{\partial T}$, the known substrate thermo-chemical expansion coefficient $\left(\alpha_{\mathrm{s}}\right)$, and a known/assumed $v_{\mathrm{f}}$ via the equation:

$$
\frac{\partial \varepsilon_{z}}{\partial T}=\alpha_{\mathrm{f}}-\frac{2 v_{\mathrm{f}}}{1-v_{\mathrm{f}}}\left(\alpha_{\mathrm{s}}-\alpha_{\mathrm{f}}\right)
$$

The resulting value for $\alpha_{\mathrm{f}}$, the measured in-plane stress $v s$. temperature behavior, and the known thermo-chemical expansion coefficient of the substrate can then be plugged into eqn (5a) to yield $M_{\mathrm{f}}$. As with the DS technique, the film's Young's Modulus, $E_{\mathrm{f}}$, can then be extracted from $M_{\mathrm{f}}$ via eqn (2) and knowledge of the film's Poisson's ratio.

\section{Experimental techniques}

Thin film fabrication and structural characterization. Here, $233 \mathrm{~nm}$-thick 10PCO films were produced on either $200 \mu \mathrm{m}$ thick (100)-oriented $9.5 \mathrm{~mol} \%$ yttria doped zirconia or $200 \mu \mathrm{m}$ thick (100)-oriented $\mathrm{MgO}$ single crystal substrates using the substrate-annealing, target-manufacturing, pulsed laser deposition (PLD), and post-deposition annealing procedures described previously in Ma and Nicholas. ${ }^{10} \mathrm{MgO}$ and YSZ were chosen for their chemical stability with ceria ${ }^{10,19,20}$ and constant oxygen nonstoichiometry ${ }^{20}$ (i.e. lack of chemical expansion) at the temperatures/oxygen partial pressures encountered here. Both 10PCO|YSZ and 10PCO|MgO samples were used for the DS measurements, while only 10PCO|YSZ samples (which avoided the potential complexities of $\mathrm{MgO}$ hydrating/dehydrating during storage and/or testing) were used for the DC technique measurements. Each film's as-deposited $25{ }^{\circ} \mathrm{C}$ preferred crystallographic orientation was examined via XRD survey scans conducted between $20^{\circ}$ and $80^{\circ}$ with a $0.01^{\circ}$ step size and a 1 second dwelling time in air on a Rigaku SmartLab Diffractometer with a $44 \mathrm{kV}$ voltage and a $40 \mathrm{~mA}$ current. Each film's as-deposited $25{ }^{\circ} \mathrm{C}$ thickness was evaluated from scanning electron microscopy (SEM) images of $5 \mathrm{~nm}$-Pt-coated fractured sample cross-sections taken with a MIRA3 field emission SEM (TESCAN Inc.) operated at $20 \mathrm{kV}$.

\section{Dual substrate technique measurements}

Here, in situ in-plane biaxial film stress measurements were conducted using the Multi-beam optical stress (MOS) sensor shown schematically in Fig. 1. Specifically, since the dense thin films analyzed here all had a film thickness $\left(h_{\mathrm{f}}\right)$ less than $\sim 1 / 1000$ th of the substrate thickness $\left(h_{\mathrm{s}}\right),{ }^{20,21}$ the in-plane film stress could be extracted from the measured bilayer wafer curvature $(\kappa)$ via Stoney's equation: ${ }^{22,23}$

$$
\sigma_{\mathrm{f}}=\kappa \frac{M_{\mathrm{s}} h_{\mathrm{s}}^{2}}{6 h_{\mathrm{f}}}
$$

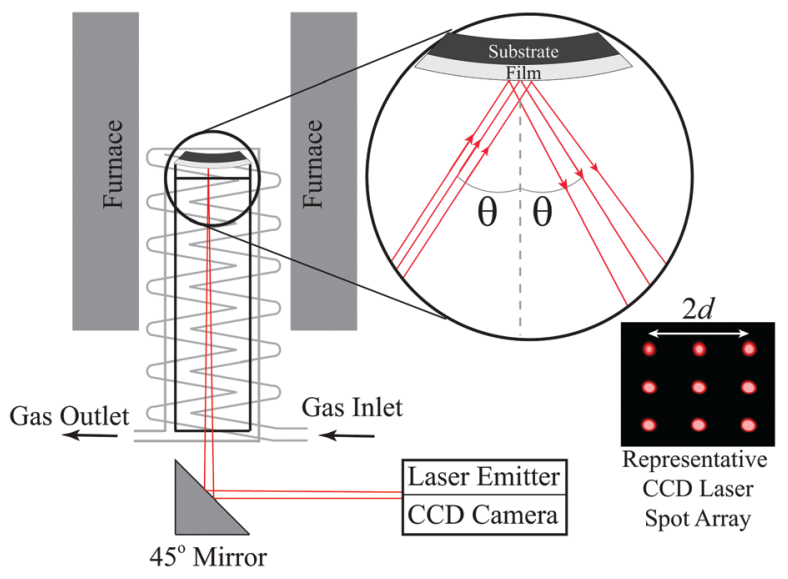

Fig. 1 Schematic of the multibeam optical stress (MOS) sensor in situ wafer curvature measurement setup used here to perform the film stress $v s$. temperature measurements. Reproduced from Nicholas ${ }^{20}$ with permission from Elsevier. 
using $h_{\mathrm{f}}$ and $h_{\mathrm{s}}$ values measured from scanning electron microscopy cross-sections (such as those shown in Fig. S1 of the ESI $\dagger$ ) and the temperature-dependent substrate biaxial modulus $\left(M_{\mathrm{S}}\right)$ values obtained from the literature ${ }^{24-26}$ and shown in Fig. S2 of the ESI. $\dagger$ These in situ curvature measurements were performed using the calibration and experimental equipment setup described in Nicholas. ${ }^{20}$ As done previously, ${ }^{10}$ stress $v s$. temperature measurements were collected in $25 \mathrm{sccm}$ of flowing synthetic air $\left(20 \% \mathrm{O}_{2}-80 \% \mathrm{Ar}\right)$ from $700{ }^{\circ} \mathrm{C}$ to $280{ }^{\circ} \mathrm{C}$ with a $0.2{ }^{\circ} \mathrm{C} \min ^{-1}$ cooling rate that, as shown in Fig. S3 of the ESI, $\dagger$ was sufficiently slow to ensure that the samples remained in thermal equilibrium while the stress $v s$. temperature data was collected. Due to the complicated, combined action of thermal and/or chemical expansion of both the film and the substrate on the stress $v s$. temperature behavior, a third order polynomial (i.e. the lowest order polynomial that adequately captured the sample behavior), and not some physical-modelpredicted equation, was used to fit the stress $v s$. temperature data. The analytical derivatives of these fits were then taken to solve for $\alpha_{\mathrm{f}}$ and $M_{\mathrm{f}}$ via eqn (5a) and (5b). The mathematical error introduced and propagated by this process was estimated using the error analysis described in the ESI $\dagger$ of Ma and Nicholas. ${ }^{10}$ Since high temperature data on the $\left(\mathrm{Y}_{2} \mathrm{O}_{3}\right)_{0.095}\left(\mathrm{ZrO}_{2}\right)_{0.905}$ thermo-chemical expansion coefficient was only available below $600{ }^{\circ} \mathrm{C},{ }^{27}$ as shown in Fig. S4 and S5 of the ESI, $\dagger$ the 25-700 ${ }^{\circ} \mathrm{C}$ YSZ $\alpha_{\mathrm{s}}$ values needed to extract $\alpha_{\mathrm{f}}$ via eqn (7) were also measured on 10PCO-supporting YSZ wafers. Values for the 25-700 ${ }^{\circ} \mathrm{C}$ thermal expansion coefficients of $\mathrm{MgO}$ were taken from Suzuki. ${ }^{28}$

Since the 10PCO $E_{\mathrm{f}}$ and $v_{\mathrm{f}}$ values in the (100) plane are directionally-dependent (as shown in Fig. S6 of the ESI $\dagger$ ) and the Poisson ratio of doped ceria remains relatively constant with temperature, ${ }^{29}$ here the measured $M_{\mathrm{f}}$ values (which are not directionally dependent in the (100)-plane as shown in Fig. S6 of the ESI $\dagger$ ) were converted to directionally-averaged (100)plane $E_{\mathrm{f}}$ values using eqn (2) by assuming the 0.42 directionally-averaged (100)-plane $v_{\mathrm{f}}$ values for room temperature ceria (derived from the $\mathrm{C}_{11}=4.03 \times 10^{12} \mathrm{dyn} \mathrm{cm}^{-2}, \mathrm{C}_{22}=$

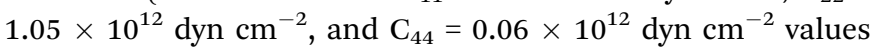
reported in Nakajima et al. $)^{30}$ also applied at the temperatures measured here.

\section{Dual characterization technique measurements}

Here, in situ out-of-plane strain measurements were conducted from the X-ray diffraction (XRD)-determined position shift of the (200) 10PCO peak shown in Fig. S7 of the ESI $\dagger$ using the equation:

$$
\varepsilon_{z}=\frac{a-a_{0}}{a_{0}}
$$

where $a$ was the (200)-determined instantaneous lattice constant of 10PCO, and $a_{0}$ was (200)-determined room temperature lattice constant at room temperature. These measurements were conducted in air on a Rigaku SmartLab Diffractometer operated at $44 \mathrm{kV}$ and $40 \mathrm{~mA}$. A Rigaku HT1500 hot stage equipped with a platinum sample holder and a R-type thermocouple was used to heat the samples during XRD measurement. After initial XRD measurements at $25{ }^{\circ} \mathrm{C}$, each 10PCO|YSZ sample was heated up to $700{ }^{\circ} \mathrm{C}$ with a $5{ }^{\circ} \mathrm{C} \mathrm{min}{ }^{-1}$ nominal heating rate and XRD measurements were conducted at $700,675,650,625,600,575,550,525$, and $500{ }^{\circ} \mathrm{C}$ from $31 \sim 34^{\circ}$ using a $0.01^{\circ}$ annular increment and a 1 second dwell time after being thermally equilibrated for 10, 10, 20, 30, 40, 40, 50 , and 60 minutes, respectively. At each temperature, at least three measurements were taken to check for, and ensure, that the samples were in thermal and chemical equilibrium. A $1{ }^{\circ} \mathrm{C} \min ^{-1}$ cooling rate was used between each analysis temperature. As shown in Fig. S7 of the ESI, $\dagger$ at each temperature, the measured XRD peaks were fitted with a Pearson VII function to determine their peak position. This function, which contains a Lorentzian component to account of the theoretically-expected shape of each XRD peak and a Gaussian shape to account for instrument-induced peak broadening ${ }^{31}$ is commonly used to determine XRD peak positions. ${ }^{32}$ After solving for $\alpha_{\mathrm{f}}$ with these parameters and an assumed 0.42 Poisson ration via eqn (7), the in-plane strain was calculated via eqn (3) and the previously described substrate $\alpha$ values. $M_{\mathrm{f}}$ was then determined by comparing this in-plane strain to the in-plane stress determined from in situ wafer curvature measurements via Hooke's Law (eqn (4)). The error introduced by this process was estimated using the error analysis described in Section 2 of the ESI. $\dagger$ As with the $M_{\mathrm{f}}$ values estimated from the DS technique, the directionally-isotropic (100) plane $M_{\mathrm{f}}$ values estimated from this DC technique were converted into directionally-averaged (100)-plane $E_{\mathrm{f}}$ values assuming that the directionally-averaged (100) plane $v_{\mathrm{f}}$ average of 0.42 also applied between 500 and $700{ }^{\circ} \mathrm{C}$.

\section{Results and discussion}

Fig. 2 shows representative XRD survey scans for the 10PCO|YSZ and 10PCO $\mid \mathrm{MgO}$ samples. This data indicates that, for both YSZ and MgO substrates, nearly all the grains in the 10PCO films exhibited a (100) preferred crystallographic orientation. In fact, an analysis made using the (200):(111) peak intensity ratios found in Fig. 2, compared to the 28.5:100 (200): (111) peak intensity ratio in JCPDS PDF \#34-394 for a collection of randomly-oriented ceria grains, suggests that (a) $\sim 100$ volume $\%$ of the PCO grains in the 10PCO|YSZ samples had a (100) orientation, and (b) $\sim 97$ volume\% of the PCO grains in the $10 \mathrm{PCO} \mid \mathrm{MgO}$ samples had a (100) orientation (while $\sim 3 \%$ volume\% had a (111) orientation). Similarly, a more accurate determination made using the integrated peak intensities shown in the pole figure XRD data of Fig. S8 of the ESI $\dagger$ suggests that $~ 97$ and 86 volume\% of the PCO grains on the $\mathrm{MgO}$ and YSZ single crystal substrates, respectively, were (100)-oriented. The preferred (100)-orientation of the PCO grains observed here is consistent with the (100) preferred crystallographic orientation ceria has exhibited on YSZ. ${ }^{10,33-37}$ and $\mathrm{MgO}^{19}$ substrates in the literature. 


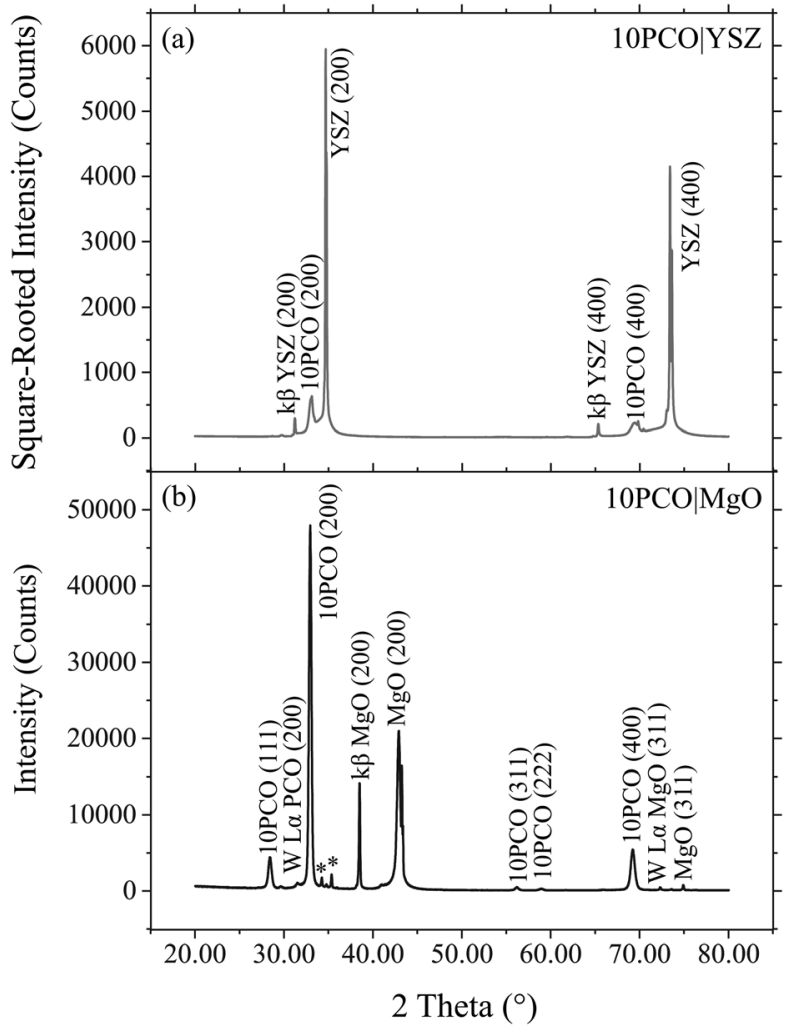

Fig. $225^{\circ} \mathrm{CX}$-Ray diffraction (XRD) survey scans of 10PCO|YSZ (top) and $10 \mathrm{PCO} \mid \mathrm{MgO}$ (bottom) showing that the 10PCO had mainly a (100) preferred crystallographic orientation. Note, the asterisk denotes the position of a (400) YSZ diffraction peak caused by tungsten $X$-rays emitted from impurity tungsten that sublimated off the electron emitter tip and onto the $\mathrm{Ni}$ target within the XRD source.

As shown by the SEM cross-sections in Fig. S1 of the ESI, $\dagger$ all the thin films produced here were dense and had laterallyuniform thicknesses of $233 \pm 8 \mathrm{~nm}$, regardless of their substrate material.

Fig. 3 shows the 10PCO $\mid \mathrm{MgO}$ and 10PCO|YSZ in-plane stress $v s$. temperature data used to calculate $\alpha, M$, and $E$ using the DS technique. As discussed in Ma and Nicholas, ${ }^{10}$ the evolution of these curve shapes $v s$. temperature were consistent with the anticipated thermal expansion coefficient differences between PCO, MgO and YSZ at various temperatures. As shown in the ESI $\dagger$ of Ma and Nicholas, ${ }^{10}$ this data was reproducible over multiple heating and cooling cycles, suggesting that all the samples remained in the linear elastic regime during testing.

Similarly, Fig. 4 shows the 10PCO|YSZ temperaturedependent strain data used to calculate $\alpha, M$, and $E$ using the DC technique.

Fig. 5 compares the thermochemical expansion coefficients measured here, to those in the literature. ${ }^{9}$ Since the thermal expansion coefficients of cubic materials like 10PCO are isotropic within the lattice, ${ }^{38}$ a direct comparison between literature data and the values measured here was possible. Curiously, the thin film 10PCO $\alpha$ values obtained from the DS technique, which increased from $\sim 12.5 \mathrm{ppm}$ at $500{ }^{\circ} \mathrm{C}$ to $\sim 17.5 \mathrm{ppm}$ at $700{ }^{\circ} \mathrm{C}$, agreed well with those obtained on bulk

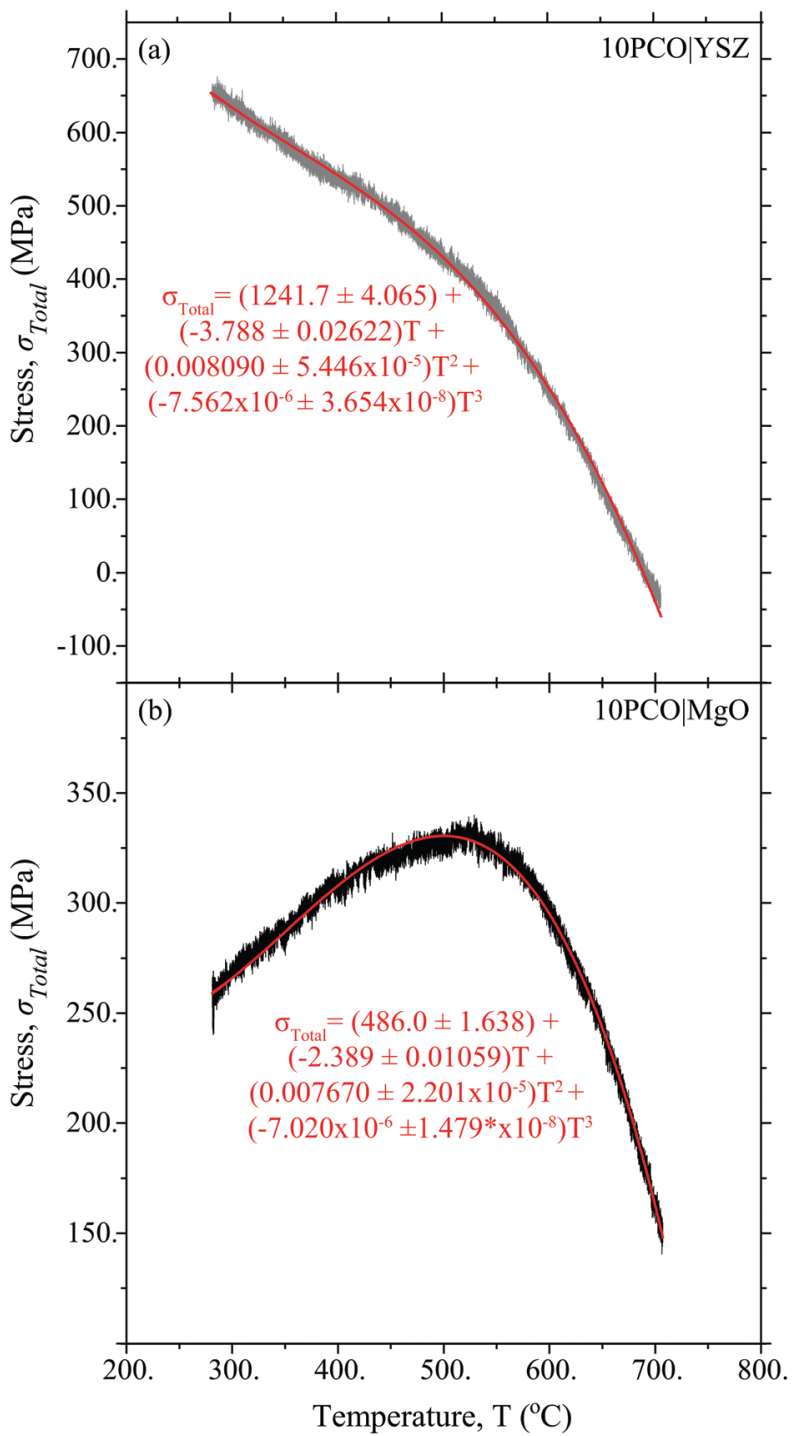

Fig. 3 Raw and fitted stress vs. temperature data used to determine $\alpha, M$, and $E$ via the DS technique. The plus or minus terms in the formulas denote the equations corresponding to plus or minus a standard deviation in the fitted data.

microcrystalline materials (via dilatometry and high temperature XRD), ${ }^{9}$ but were higher than the thin film 10PCO $\alpha$ values obtained from the DC technique. Although the exact reasons for this are unclear, multiple studies have suggested that the grain boundaries of ceria are easier to reduce than the lattice interior. ${ }^{39,40}$ Hence, the low angle grain boundaries/defective regions around the large amount of threading dislocations known to exist in YSZ supported PCO thin films ${ }^{17}$ (and suggested by the preferred orientation/epitaxy indicated by Fig. 2) may behave like they are in a lower pO2 portion of the ceria Brouwer diagram, ${ }^{41}$ and hence might be expected to possess a higher thermochemical expansion coefficient than the bulk. Since these defects are mainly oriented perpendicular to the plane of the film, this situation would violate the assumption of an isotropic $\alpha$ used in the DC technique. The increasing thermochemical expansion values that occur in 10PCO as the 

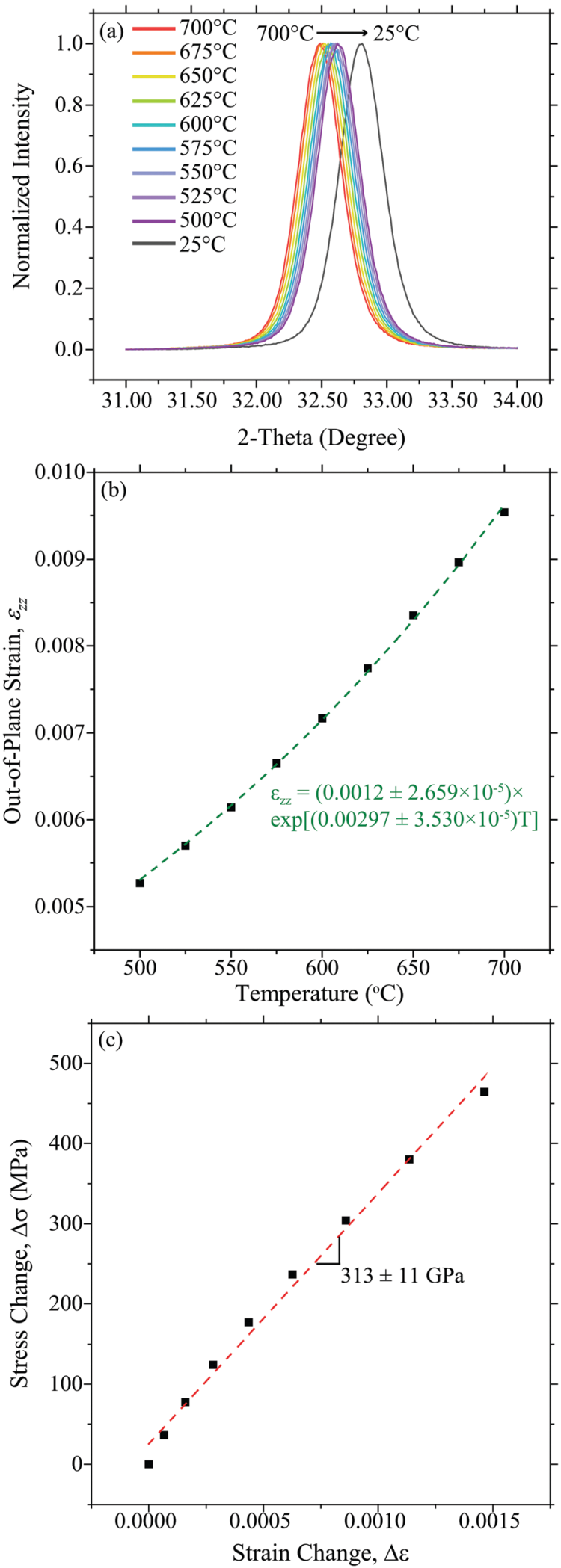

Fig. 4 The (a) out-of-plane XRD-determined shift of the (200) 10PCO peak, (b) the corresponding total out-of-plane engineering strain, and corresponding fit, calculated from that shift (assuming an eqn (9) zero-strain state at $25^{\circ} \mathrm{C}$ ) used to obtain $\alpha_{f}$ via eqn (7), and (c) the comparison of the in-plane strain (calculated from that $\alpha_{f}$ via eqn (3)) vs. the in-plane stress (obtained via in situ 10PCO|YSZ wafer curvature measurements) used to determine $M$ in the DC technique.

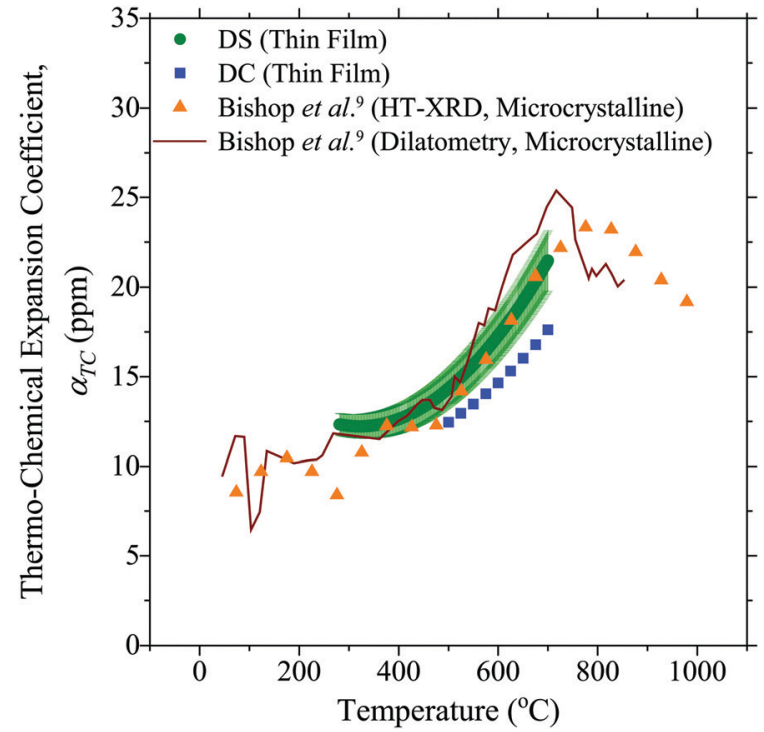

Fig. 5 The thermo-chemical expansion coefficient of 10PCO measured here, compared to the literature. ${ }^{9}$ Note, the estimated error bars on the DC data points are smaller than the symbol size, and HT-XRD denotes high temperature X-ray diffraction.

material is heated from 500 to $700{ }^{\circ} \mathrm{C}^{10}$ (as the material becomes more oxygen deficient; i.e. as it acts as if it's in a lower $\mathrm{pO} 2$ portion of the ceria Brouwer diagram) is consistent with higher Fig. $5 \alpha$ values for the DS compared to the DC technique. (Note, the $\pm 8 \%$ measurement error bars around the DS $\alpha$ values, and the $<1 \%$ measurement error bars around the DC $\alpha$ values are similar in size to those reported in other studies utilizing these techniques. ${ }^{16,42}$ That being said, the DC error bars may actually be larger than $1 \%$, due to preferred orientation of the films shown in Fig. 2 violating the assumption in the DC technique that the $\alpha_{\mathrm{f}}$ in the plane of the film, and perpendicular to it, are equal).

Fig. 6a compares the 10PCO biaxial moduli obtained here from the DS and the DC techniques with previous biaxial moduli values from the literature. For all the measurements here, the measured $M$ values were roughly constant at $\sim 300 \mathrm{GPa}$ from $500-700{ }^{\circ} \mathrm{C}$, suggesting that the $10 \mathrm{PCO}$ elastic constants are largely insensitive to the $\sim 5 \%$ change in the 10 PCO lattice oxygen stoichiometry known to occur in these films over this temperature range. ${ }^{10}$ This insensitivity to oxygen nonstoichiometry may also explain why the $M$ values measured from the DS and DC techniques agreed so well with each other (since any local oxygen stoichiometry differences brought about by in-plane versus out-of-plane structural differences would have no effect).

Fig. 6b compares the 10PCO Young's moduli obtained here from the DS and the DC techniques with the literature. ${ }^{17,34,35,43}$ For all the measurements here, the DS and DC techniques yielded average (100) direction 10PCO values that were roughly constant at $\sim 175 \mathrm{GPa}$ from $500-700{ }^{\circ} \mathrm{C}$. It is important to note that even though they came from the same biaxial modulus, the $\sim 175$ GPa DS-determined Young's modulus values here are 


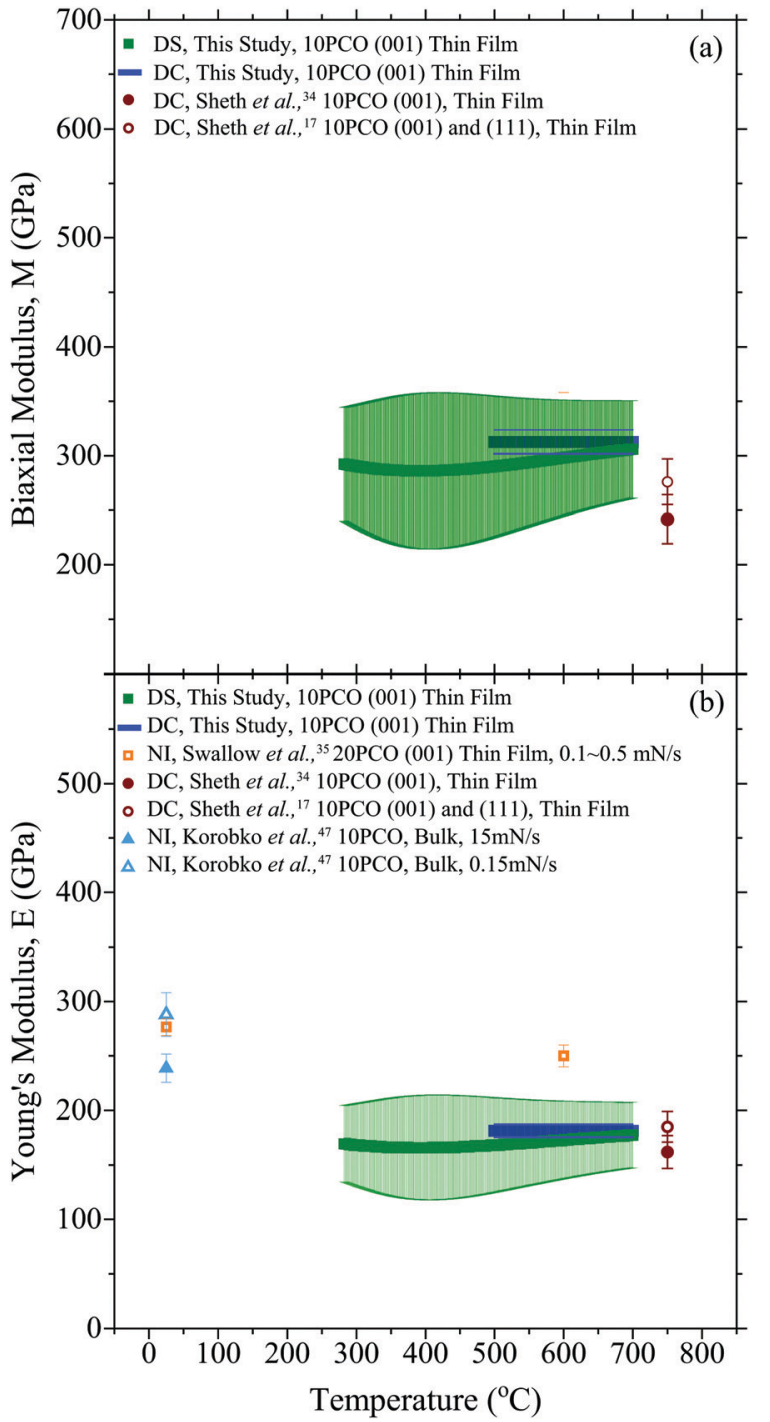

Fig. 6 The (a) biaxial modulus, and (b) Young's modulus of 10PCO measure here, compared to the literature. ${ }^{17,34,35,43} \mathrm{NI}$ denotes values obtained from nano-indentation, while the other abbreviations have their previously defined meanings. Note, the estimated error bars on the DC data points are smaller than the symbol size.

more accurate than the $\sim 200 \mathrm{GPa}$ DS-determined values from Ma and Nicholas, ${ }^{10}$ because a more correct Poisson ratio of 0.42 for (100)-oriented ceria (corresponding to the preferred film orientation shown in Fig. 2) was used to extract the Young's Modulus from the biaxial modulus here (via eqn (2)), instead of the 0.33 average Poisson's ratio value for randomly-oriented polycrystalline used previously for PLD 10PCO thin films on YSZ and/or sapphire substrates. ${ }^{10,34,35}$ The Young's moduli measured here agreed well with the DC data reported by Sheth et $a l .{ }^{17,34}$ but they did not agree with the nano-indentation data of either Swallow et al. ${ }^{35}$ or Korobko et al., ${ }^{43}$ presumably due to the different 10PCO doping levels examined in Swallow et al. ${ }^{35}$ and/or the loading-rate-dependent $E$ values obtained via nanoindentation $^{43}$ as a result of the elastic dipole reorientation known to occur in ceria below $\sim 250{ }^{\circ}$ C. $^{18,44}$

\section{Conclusions}

This work demonstrated that similar thermochemical expansion coefficients, biaxial moduli, and Young's moduli values could be obtained using either (1) in situ stress $v s$. temperature measurements of (100)-oriented $\mathrm{Pr}_{0.1} \mathrm{Ce}_{0.9} \mathrm{O}_{1.95-x}$ thin films on either YSZ or MgO single crystal substrates, or (2) combined in situ stress $v s$. temperature and in situ strain $v s$. temperature measurements on a single (100)-oriented $\mathrm{Pr}_{0.1} \mathrm{Ce}_{0.9} \mathrm{O}_{1.95-x}$ thin film on YSZ. While they both had their limitations (the potentially-violated assumption of "identical substrates on different substrates" in the DS technique, the potentiallyviolated assumption of isotropic thermochemical expansion coefficients in the DC technique, etc.), both techniques indicated that in the (100) plane of $\operatorname{Pr}_{0.1} \mathrm{Ce}_{0.9} \mathrm{O}_{1.95-x}$ from 500 to $700{ }^{\circ} \mathrm{C}$, (1) the directionally-averaged thermo-chemical expansion coefficient increased from $\sim 12.5$ to $\sim 17.5 \mathrm{ppm},(2)$ the biaxial modulus was roughly constant at $\sim 300 \mathrm{GPa}$, and (3) the directionally-averaged Young's modulus was roughly constant at $\sim 175 \mathrm{GPa}$. These high temperature materials properties could be useful for designing Solid Oxide Electrolysis Cells, Solid Oxide Fuel Cells, or other electrochemical devices utilizing high temperature $\operatorname{Pr}_{0.1} \mathrm{Ce}_{0.9} \mathrm{O}_{1.95-x}$ thin films.

\section{Conflicts of interest}

There are no conflicts to declare.

\section{Acknowledgements}

This work was generously supported by the Department of Energy under Award Number DE-FE0023315. The microscopy work was conducted at the Michigan State Composites Center, which is supported by the NSF Major Instrumentation Program and Michigan State University. The authors would like to thank Dr Timothy Hogan and Mr Karl Dersch of Michigan State University for assistance with the thin film deposition. The authors would also like to thank Dr Alexandra Zevalkink, Dr Elias Garratt, and Mr Shengyuan Bai for assistance with the XRD measurements.

\section{References}

1 A. Atkinson, S. A. Barnett, R. J. Gorte, J. T. S. Irvine, A. J. McEvoy, M. B. Mogensen, S. Singhal and J. Vohs, Nat. Mater., 2004, 3, 17-27.

2 M. Hecht, J. Hoffman, D. Rapp, J. McClean, J. SooHoo, R. Schaefer, A. Aboobaker, J. Mellstrom, J. Hartvigsen, F. Meyen, E. Hinterman, G. Voecks, A. Liu, M. Nasr, J. Lewis, J. Johnson, C. Guernsey, J. Swoboda, C. Eckert, C. Alcalde, M. Poirier, P. Khopkar, S. Elangovan, M. Madsen, P. Smith, C. Graves, G. Sanders, K. Araghi, M. D. Juarez, D. Larsen, J. Agui, A. Burns, K. Lackner, R. Nielsen, T. Pike, B. Tata, K. Wilson, T. Brown, T. Disarro, R. Morris, R. Steinkraus, R. Surampudi, T. Werne and A. Ponce, Space Sci. Rev., 2021, 217, 76. 
3 W. C. Chueh, C. Falter, M. Abbott, D. Scipio, P. Furler, S. M. Haile and A. Steinfeld, Science, 2010, 330, 1797-1801.

4 J. Kaspar, P. Fornasiero and M. Graziani, Catal. Today, 1999, 50, 285-298.

5 P. Jasinski, T. Suzuki and H. U. Anderson, Sens. Actuators, B, 2003, 95, 73-77.

6 A. Younis, D. Chu, X. Lin, J. Yi, F. Dang and S. Li, ACS Appl. Mater. Interfaces, 2013, 5, 2249-2254.

7 V. V. Kharton, A. V. Kovalevsky, A. P. Viskup, A. L. Shaula, F. M. Figueiredo, E. N. Naumovich and F. M. B. Marques, Solid State Ionics, 2003, 160, 247-258.

8 N. Özer, Sol. Energy Mater. Sol. Cells, 2001, 68, 391-400.

9 S. R. Bishop, H. L. Tuller, Y. Kuru and B. Yildiz, J. Eur. Ceram. Soc., 2011, 31, 2351-2356.

10 Y. Ma and J. D. Nicholas, Phys. Chem. Chem. Phys., 2018, 20, 27350-27360.

11 L. J. Gauckler, M. Gödickemeier and D. Schneider, J. Electroceram., 1997, 1, 165-172.

12 P. S. Manning, J. D. Sirman and J. A. Kilner, Solid State Ionics, 1997, 93, 125-132.

13 M. Kamiya, E. Shimada, Y. Ikuma, M. Komatsu and H. Haneda, J. Electrochem. Soc., 2000, 147, 1222-1227.

14 T. F. Retajczyk and A. K. Sinha, Appl. Phys. Lett., 1980, 36, 161-163. 15 M. M. De Lima, R. G. Lacerda, J. Vilcarromero and F. C. Marques, J. Appl. Phys., 1999, 86, 4936.

16 J. Thurn and M. P. Hughey, J. Appl. Phys., 2004, 95, 7892-7897. 17 J. Sheth, D. Chen, J. J. Kim, W. J. Bowman, P. A. Crozier, H. L. Tuller, S. T. Misture, S. Zdzieszynski, B. W. Sheldon and S. R. Bishop, Nanoscale, 2016, 8, 16499-16510.

18 T. Das, J. D. Nicholas, B. W. Sheldon and Y. Qi, Phys. Chem. Chem. Phys., 2018, 20, 15293-15299.

19 N. Savvides, A. Thorley, S. Gnanarajan and A. Katsaros, Thin Solid Films, 2001, 388, 177-182.

20 J. D. Nicholas, Extreme Mech. Lett., 2016, 9, 405-421.

21 L. B. Freund and S. Suresh, Thin Film Materials: Stress, Defect Formation and Surface Evolution, Cambridge University Press, New York, NY, 2003.

22 G. G. Stoney, Proc. R. Soc. London, Ser. A, 1909, 82, 172-175.

23 J. D. Nicholas, in Electro-Chemo-Mechanics of Solids, ed. S. Bishop, D. Marrocchelli, N. Perry and B. Sheldon, Springer, New York, 2017, ch. 5, pp. 103-136, DOI: 10.1007/978-3-319-51407-9_5.

24 D. G. Isaak, O. L. Anderson and T. Goto, Phys. Chem. Miner., 1989, 16, 704-713.
25 P. J. Botha, J. C. H. Chiang, J. D. Comins, P. M. Mjwara and P. E. Ngoepe, J. Appl. Phys., 1993, 73, 7268-7274.

26 S. V. Sinogeikin, D. L. Lakshtanov, J. D. Nicholas, J. M. Jackson and J. D. Bass, J. Eur. Ceram. Soc., 2005, 25, 1313-1324.

27 H. Hayashi, T. Saitou, N. Maruyama, H. Inaba, K. Kawamura and M. Mori, Solid State Ionics, 2005, 176, 613-619.

28 I. Suzuki, J. Phys. Earth, 1975, 23, 145-159.

29 T. Kushi, K. Sato, A. Unemoto, S. Hashimoto, K. Amezawa and T. Kawada, J. Power Sources, 2011, 196, 7989-7993.

30 A. Nakajima, A. Yoshihara and M. Ishigame, Phys. Rev. B: Condens. Matter Mater. Phys., 1994, 50, 13297-13307.

31 B. D. Cullity, Elements of X-Ray Diffraction, Addison-Wesley, New York, 2nd edn, 1978.

32 M. M. Hall, V. G. Veeraraghavan, H. Rubin and P. G. Winchell, J. Appl. Crystallogr., 1977, 10, 66-68.

33 D. Chen, S. R. Bishop and H. L. Tuller, J. Electroceram., 2012, 28, 62-69.

34 J. Sheth, D. Chen, H. L. Tuller, S. T. Misture, S. R. Bishop and B. W. Sheldon, Phys. Chem. Chem. Phys., 2017, 19, 12206-12220.

35 J. G. Swallow, J. J. Kim, M. Kabir, J. F. Smith, H. L. Tuller, S. R. Bishop and K. J. Van Vliet, Acta Mater., 2016, 105, 16-24.

36 D. Chen, S. R. Bishop and H. L. Tuller, Adv. Funct. Mater., 2013, 23, 2168-2174.

37 J. J. Kim, S. R. Bishop, N. J. Thompson, D. Chen and H. L. Tuller, Chem. Mater., 2014, 26, 1374-1379.

38 J. F. Nye, Physical Properties of Crystals: Their Representation by Tensors and Matrices, Oxford University Press, New York, 1985.

39 B. W. Sheldon, S. Mandowara and J. Rankin, Solid State Ionics, 2013, 233, 38-46.

40 Y. M. Chiang, E. B. Lavik, I. Kosacki, H. L. Tuller and J. Y. Ying, Appl. Phys. Lett., 1996, 69, 185-187.

41 S. R. Bishop, T. S. Stefanik and H. L. Tuller, Phys. Chem. Chem. Phys., 2011, 13, 10165-10173.

42 Y. Kuru, S. R. Bishop, J. J. Kim, B. Yildiz and H. L. Tuller, Solid State Ionics, 2011, 193, 1-4.

43 R. Korobko, S. K. Kim, S. Kim, S. R. Cohen, E. Wachtel and I. Lubomirsky, Adv. Funct. Mater., 2013, 23, 6076-6081.

44 A. Kossoy, Y. Feldman, R. Korobko, E. Wachtel, I. Lubomirsky and J. Maier, Adv. Funct. Mater., 2009, 19, 634-641. 